\title{
Store Management Practices in Medium Scale Engineering Firm
}

\author{
Mr. Shrikant S. Karanjkar \\ Assistant Professor, Department of Management Studies (MBA), \\ Rajarambapu Institute of Technology, Rajaramnagar, Urun Islampur, Maharashtra, India
}

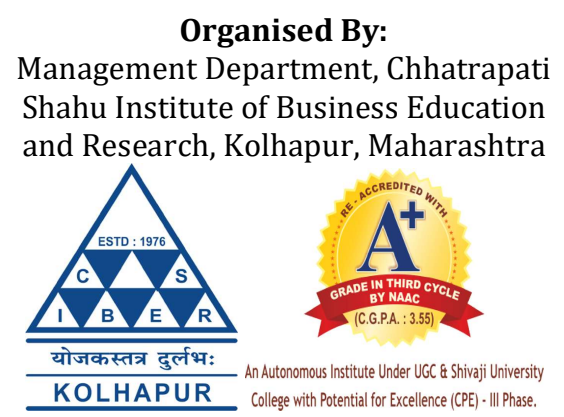

How to cite this paper: Mr. Shrikant S. Karanjkar "Store Management Practices in Medium Scale Engineering Firm" Published in International Journal of Trend in Scientific Research and Development (ijtsrd), ISSN: 2456-6470, Special Issue | Fostering Innovation, Integration and Inclusion Through Interdisciplinary Practices in Management, March 2019, pp.149-151, URL:

https://www.ijtsrd. com/papers/ijtsrd2 3088.pdf

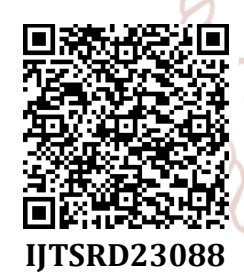

\section{Scope of the Study}

1. The study is only limited to engineering manufacturing firm situated in Satara district.

2. The study mainly focuses on store management practices in motor manufacturing industry.

\section{Research Methodology}

In this study, primary as well as secondary sources of data have been used.

\section{A. Primary Data: -}

Primary data refers to the data collected from primary sources i.e. the data collected by the investigation and observation primary data is also called as original data. since, it is collected for the first time by a person, who is going to use them. The researcher has collected the primary data through discussion with respective officers and employees.

B. Secondary Data: -

The secondary data is already available in a published from research work in the process has been done

\section{INTRODUCTION}

space, room and the building where various types of materials, semi-finished production and sale or used for consumption is called a Store or Warehouse. Finished parts or products ready for shipment and sale are called stock and they eparately stored in a place called stock room. Each and every type of materia store separate place, bin or container and a room to keep it and the type of material enters directly at the production facility after its purchase and rest is upplied to the stores. The part coming out from production facility, some of them the production center or facility and rest are stored. In the same way, compone facility are sent to assembly center and rest are stored. Finally, the output is the final product sent to stock or sell. This process of parious materials and parts is called Stores facility the maintains the continuity in production.

\section{Objective of the Study}

1. To study the store management practices in engineering manufacturing firm.

2. To find the effectiveness of inventory techniques with regard to supply of

3. To study the material handling technique in the organization.

4. To study material inward and outward process in store. through collection of data from the staff members of the company / organization. The secondary data is collected through different report \& document of the Company.

Sample Design: -

he most of the industries are mainly produces electric motors and water pumps. The researcher has collected the data about the material requirement of these products and inward and outward process of these products.

\section{Literature Review}

1. Automated store ordering has been offered as a potential solution to many store level problems: Automation could improve availability, decrease inventories, and reduce the time and labor required for ordering. However, despite the potential advantages, it seems that the majority of retailers have only just started to implement automated ordering systems at store level. Furthermore, very little published information can be found on store level processes, not to mention automated store ordering. Therefore, well- 
International Journal of Trend in Scientific Research and Development (IJTSRD) @ www.ijtsrd.com eISSN: 2456-6470

documented research on how and if conventional inventory management practices can be applied at store level operations should be extremely engrossing both from academic and business viewpoints. (Source-thesis efficient store Ordering-Carl falck)

2. Inventory management - The word 'inventory' has been defined in many ways, as indicated in the literature. Three definitions have been chosen seem to be more appropriate to the topic developed in this dissertation. "inventories are stockpiles of raw materials, suppliers, components, work in process, and finished goods that appear at numerous points throughout a firms production and logistic channel" ( ballou 2004)

3. According to chase, Jacobs and aquilano (2004), inventory is the stock of any item or resource used in an organization. An inventory system is the set of policies and controls that monitor levels of inventory and determine what levels should be maintained, when stock should be replenished, and how large order should be.

4. It all starts with a suitable lay out design of stores. Depending upon the nature of items used for processing by the organization the lay out and type of stores are selected. For example, a process that requires use of raw materials, not costly enough, an open and nearby stores with truck / rail inside movement possibility Once the material has been received and cleared through inspection and accepted for use, it needs safe custody till it's actually used. It calls for a separate physical storage space, open or closed, as per need. It maintains all documents that are able to trace an item, show all its details and preserve it up to its shelf life in the manner prescribed or till it is issued for use. (lucay 2003)

VI. Data Analysis and Interpretation Material Inward Process (Through SAP Software)

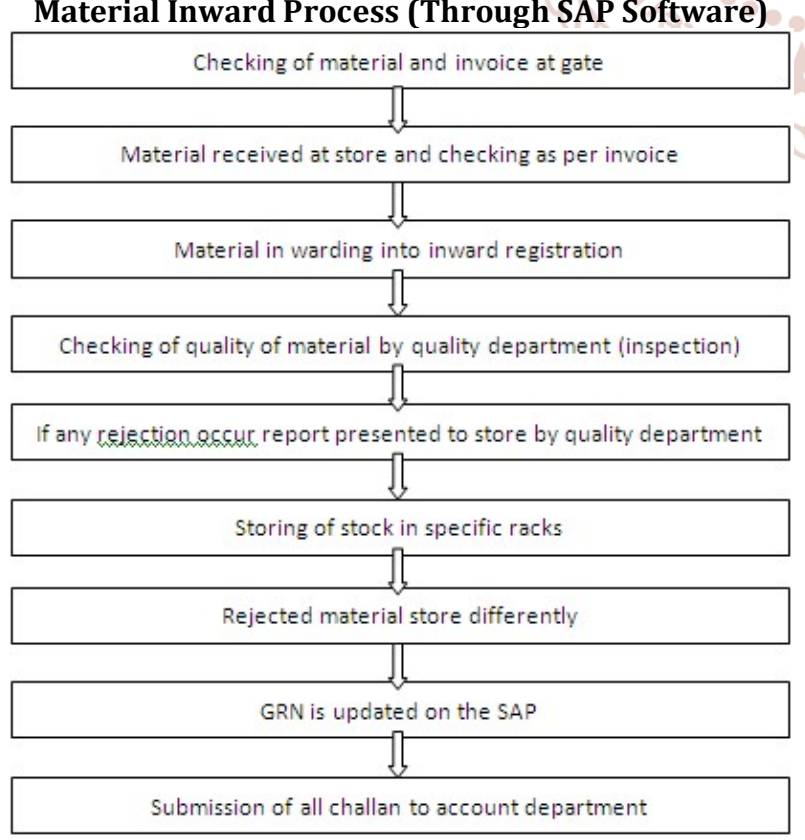

Material Outward Process through SAP Software

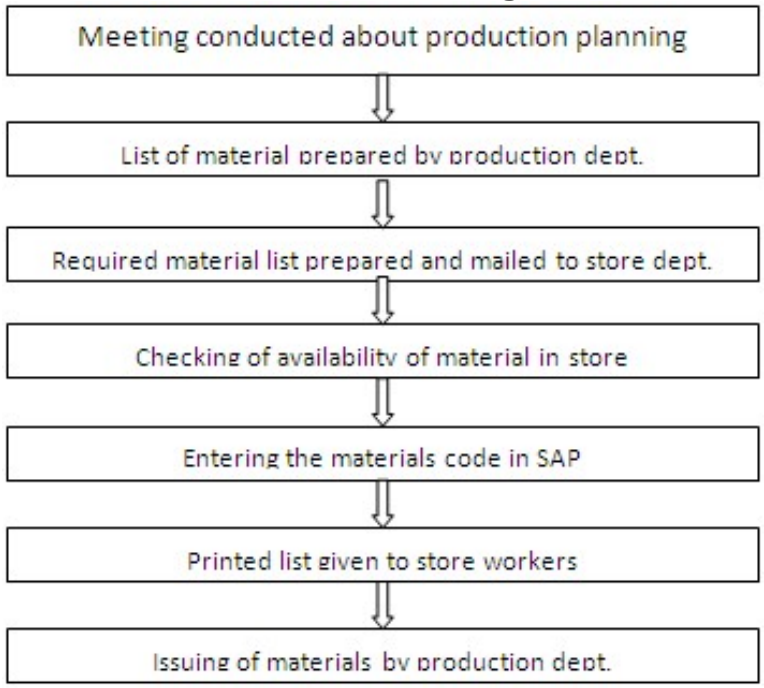

Monthly Production of Water Pumps \begin{tabular}{|l|l|} 
Month & Production In Unit
\end{tabular}

\begin{tabular}{|c|l|}
\hline November2014 & 32000 \\
\hline December & 25000 \\
\hline January2015 & 24910 \\
\hline February & 27880 \\
\hline March & 28940 \\
\hline April & 30100 \\
\hline May & 26780 \\
\hline
\end{tabular}

Monthly Production of Waterpumps

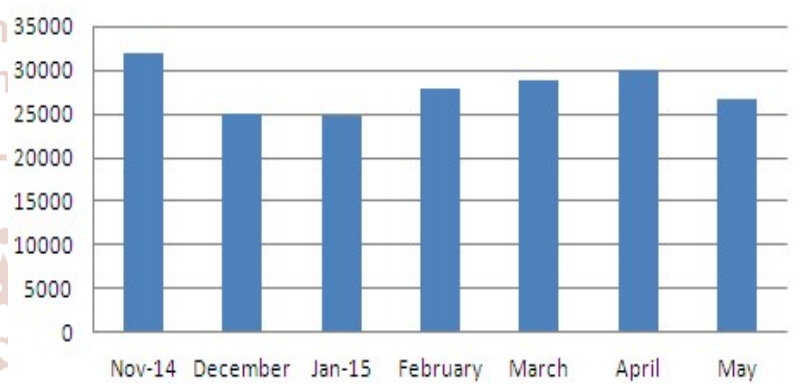

Interpretation - The graph interprets monthly production of water pumps for last 6 months. Nov-14 32000 units, December 25000 units, January 201524910 units February 27880 units. March 28940 units in month of April 30100 units and 26780 units in may2015.

Daily requirement of shaft in kpml for specific motor
\begin{tabular}{|c|c|c|}
\hline Product & Shaft Size & Quantity \\
\hline Mini 40s water pump & Shaft mini 40s & 1000 \\
\hline Jalraj water pump & Shaft jalraj & 980 \\
\hline Mini50s water pump & Shaft mini 50s & 900 \\
\hline KI-75 motor & KI-75 shaft & 1000 \\
\hline KI-90 motor & KI-90 shaft & 700 \\
\hline KI-120 motor & KI-120 shaft & 550 \\
\hline KI-180 motor & KI-180 shaft & 25 \\
\hline KI-280 motor & KI-280 shaft & 10 \\
\hline
\end{tabular}


Daily Requirement of Shaft

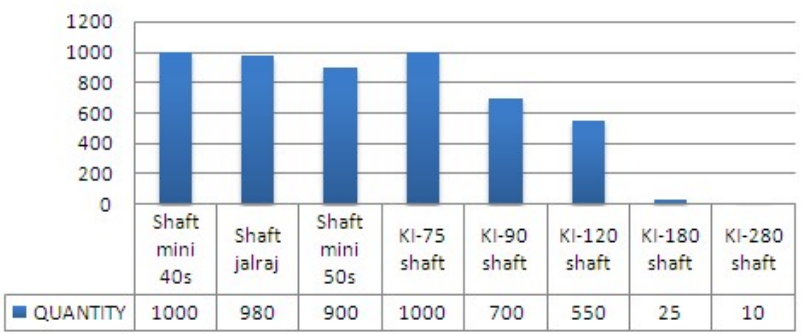

Interpretation - Above graph shows the daily shaft requirement of shaft. For mini40s 1000 units, jalraj 980 units, mini50s 900 units, KI-75 1000 units, KI-90 700 units KI-120 550 units and 25 and 10 in KI-180 KI-280 respectively.

Daily Requirement of Fan Cover

\begin{tabular}{|c|c|c|}
\hline Product & Fan Cover & Quantity \\
\hline KI-75 MOTOR & Fan cover for KI-75 & 1000 \\
\hline KI-90 MOTOR & Fan cover for KI-90 & 700 \\
\hline KI-100 MOTOR & Fan cover for KI-100 & 700 \\
\hline KI-120 MOTOR & Fan cover for KI-120 & 650 \\
\hline KI-180 MOTOR & Fan cover for KI-180 & 25 \\
\hline KI-190 MOTOR & Fan cover for KI-190 & 20 \\
\hline KI-220 MOTOR & Fan cover for KI-220 & 15 \\
\hline KI-255 MOTOR & Fan cover for KI-255 & 10 \\
\hline
\end{tabular}

Daily Requirement of Fan Cover

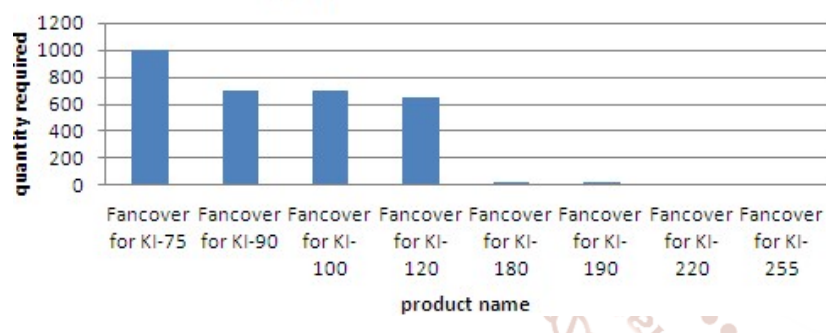

Interpretation - The graph interprets the daily requirement of fan cover at kpml. For ki-75 motor 1000 units, ki-90 700 units, ki-100 700 units, ki-120 650units, ki-180 25units, ki-190 20 units \& KI-220 \& KI-255 are having 15 \& 10 respectively.

\section{Findings}

1. It is observed that producing largely water pumps and electric motors in the company.

2. It is observed that water pumps are the highest production at the company.

3. It is observed that the company using advanced material handling equipment in store.

4. Store department and other department are fully integrated with each other.

5. Security, safety and wastage of material is very low at company.

6. The company is using ERP system for their effective working.

\section{Conclusion}

Store department of kpml is using advanced material equipment. Advanced ERP system has reduced lots paper work in kpml. SAP system has improved the effective material inward and outward process in kpml. The store manager is able to know the in stock material with the help of kpml. A sap system provides information related to the suppliers of firm and excise duties of each material

\section{References: -}

[1] K. Ahwatthappa - Production \& Operations Management, Himalaya Publishing House, New Delhi.

[2] Prof. M. T. Telsang - Industrial Engineering \& Production Management, S. Chand \& Company Ltd., New Delhi

[3] S. N. Cherry, "Production \& Operations Management, Tata McGraw-Hill Education Pvt. Ltd. New Delhi

[4] Chunawala Patel, "Production \& Operations Management", Himalaya Publishing House, New Delhi.

[5] R. Pannerselvam,"Production \& Operations Management", Eastern Economy Edition, New Delhi.

Copyright (C) 2019 by author(s) and International Journal of Trend in Scientific Research and Development

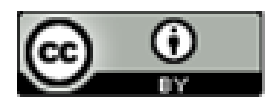
Journal. This is an Open Access article distributed under the terms of the Creative Commons Attribution License (CC BY 4.0) (http://creativecommons.org/licenses/by/4.0) 